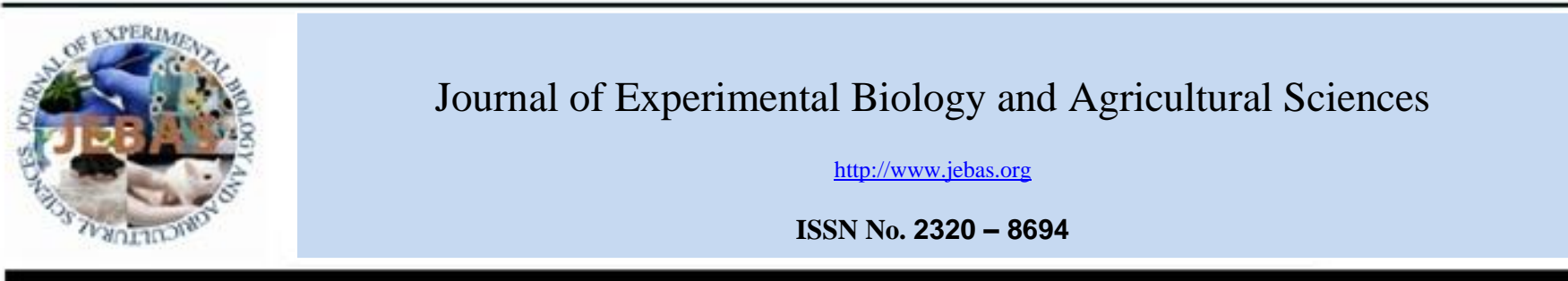

\title{
CYSTIC HYDATIDOSIS IN KIDNEY OF SHEEP: PREVALENCE AND HISTOPATHOLOGICAL STUDY
}

\author{
Biology Department, Faculty of Science, University of Jeddah, Jeddah,Saudi Arabia \\ Received - July 23, 2019; Revision - August 30, 2019; Accepted -September 15, 2019 \\ Available Online - October 15, 2019
}

Muslimah, N. ALsulami*, Nafisa Mohammd Batarfi

DOI: http://dx.doi.org/10.18006/2019.7(5).505.512

\section{KEYWORDS}

Echinococcosis

Prevalence

Age

Sex

Kidney

Histopathology

\begin{abstract}
Cystic echinococcosis (CE), also known as hydatid disease, is a zoonotic disease worldwide, including Saudi Arabia. Echinococcosis is of great importance to human health and has a significant effect on the economies of countries. In current study, total 23902 slaughtered sheep carcasses were examined in Jeddah city, Saudi Arabia for the effect of age and sex on the prevalence of infection and the histological examination of kidney. Results of the current study revealed statistically significant difference in the prevalence of kidney hydatidosis in infected sheep. Rate of infection depend on the sex and age, among the investigated kidney samples, female sheep had the highest prevalence of infection as compared to males. Further, in case of sheep age, highest prevalence was reported in the sheep aged more than 2 years while lowest prevalence was reported in sheep aged less than 1 year. The histopathological examination showed sever degeneration in kidney tissues and marked mononuclear infiltrations. Current study provides an insight into sheep infection with kidney cysts suggest that sheep are a potential source of hydatidosis transmission to other animals.
\end{abstract}

* Corresponding author

E-mail: mnal-sulami@uj.edu.sa; dr.nafisa1_m@hotmail.com (Nafisa Mohammd Batarfi)

Peer review under responsibility of Journal of Experimental Biology and Agricultural Sciences.

Production and Hosting by Horizon Publisher India [HPI] (http://www.horizonpublisherindia.in/).

All rights reserved.
All the articles published by Journal of Experimental Biology and Agricultural Sciences are licensed under a Creative Commons Attribution-NonCommercial 4.0 International License Based on a work at www.jebas.org.

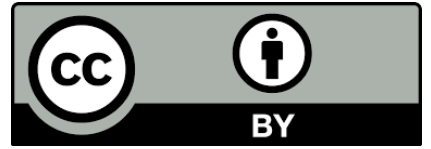




\section{Introduction}

Cystic echinococcosis (CE), also termed hydatid disease, is a worldwide zoonotic disease, including Saudi Arabia (AbdelBaki et al., 2018). It is caused by Echinococcus granulosus larvae that pose a serious problem to human health and livestock and lead to significant economic loss (Yang et al. 2015). According to Abdel-Baki et al. (2016), Echinococcus worm completed life cycle in two-hosts, where canines act as end-hosts and domestic livestock serve as intermediate hosts. Further, Echinococcus granulosus contains nine genotypes (G1-G9) or strains (Schurer et al., 2013). All these genotypes could cause $\mathrm{CE}$ in intermediate host also. Among the identified nine genotypes, the livestock genotypes (G1-G3) have global distribution and are responsible for extensive economic damage due to livestock production losses and human illness. Sheep and goats are the most relevant domestic intermediate host for genotype G1; this genotype may also affect cattle, camels and donkeys (Nakao et al., 2013; Romig et al., 2015).

Echinococcosis significantly affects the economies of many countries where livestock production is a major part of agriculture and when livestock production mainly depends on an extended pasture system. The greater contact in rural communities between man, dogs and sheep makes the parasite life cycle more likely to be completed in this environment (Toulah et al., 2017).

In Saudi Arabia, hydatidosis in sheep was $2.5 \%$ in Al Qasim, $12.61 \%$ in Al Baha, $6.8 \%$ in Najran, $13.5 \%$ in Al Taif and $2.83 \%$ in Dammam (El-Ghareeb et al., 2017). Unfortunately, $\mathrm{CE}$ in the intermediate hosts such as sheep, goat and cattle is usually asymptomatic and unclear to farmers in the live animals. There are different methods for diagnosis and detection of CE in livestock. Serodiagnosis is one of these methods but do not provide a sufficiently specific and sensitive practical pre-mortem alternative. Also, ultrasound screening programmes for $\mathrm{CE}$, has not been the preferred approach for monitoring in poor endemic areas and during control schemes. Accordingly, the most dependable method is to detect the cyst in meat screening or at inspection after death of the animals (Criage et al., 2015). Thus, the slaughterhouse is the suitable place for scanning hydatidosis in livestock (Almalki et al., 2017).

Therefore, the main objectives of the current study was to locate the prevalence rate of the infected kidney by cystic hydatidosis together with the effect of age and sex on the prevalence of the infection and the histopathological examination of kidney in Jeddah sheep slaughtered in Jeddah city, Saudi Arabia.

\section{Materials and Methods}

\subsection{Study area \& Sampling}

This work was carried out on the kidney of slaughtered sheep in the city of Jeddah, Saudi Arabia. The Global Positioning System (GPS) of the slaughterhouse was $21^{\circ} 32^{\prime} 36 \mathrm{~N}$ and $39^{\circ} 10^{\prime} 22 \mathrm{E}$. The abattoir was visited periodically to examine the kidney of slaughtered sheep for the presence of hydatid cysts. A total of 23902 sheep kidney were inspected and recorded for cystic lesions including age and sex for each animal over one year from the beginning of January 2017 until the end of December 2017. Infected kidneys were transferred with procedures counseled by WHO (1993) to the lab of Parasitology, Parasitology Department, College of Science, Jeddah University. All samples were examined histopathologically.

\subsection{Kidney samples}

The infected kidney samples were dissected and fixed in $10 \%$ formaldehyde solution and processed to obtain paraffin blocks. Five $\mu \mathrm{m}$-thick sections were cut and stained with Hematoxylin and Eosin stain $(\mathrm{H} \& \mathrm{E})$ for examination of overall morphology Bancroft \& Gamble (2008).

\subsection{Statistical analysis}

Statistical analysis was carried out using Graph Pad prism, software program, version 5.0. (2007) Inc., CA, USA. Age and sex on hydatid infestation and the prevalence for hydatidosis were analyzed and tested for significance using the " $\mathrm{t}$ " test and the Pearson's $\chi 2$ (Chi-square). $\mathrm{P}$ values $<0.05$ were considered statistically significant.

\section{Results}

\subsection{Prevalence of hydatidosis among kidney of slaughtered sheep}

In current study, scanning of hydatidosis in sheep kidney was carried out in slaughtered animal in slaughterhouse of Jeddah city, Saudi Arabia. The results recorded throughout the year (Table 1) revealed that the overall prevalence of infected sheep at Jeddah abattoirs was $1.17 \%$ (281/23902). The statistical analysis results revealed that the prevalence of infected kidney varies significantly $(\mathrm{P}<0.05)$ according to sex (Table 1). Female sheep had the highest prevalence of infection at $(55.51 \%)$ as compared to males $(44.48 \%)$.

In addition, the results revealed that infection differed according to the sheep's age, highest prevalence was reported in sheep aged more than 2 years old $(50.53 \%)$ followed by sheep aged $1-2$ years $(30.96 \%)$ while the lowest prevalence was in sheep aged less than

1 year $(18.50 \%)$. The statistical analysis confirmed that these differences were statistically significant $(\mathrm{P}<0.05)$ (Table 1). 
Table 1 The Prevalence of hydatid cysts affected kidney (Overall, age and sex dependent) among slaughtered sheep in Jeddah Abattoir, Saudi Arabia.

\begin{tabular}{|c|c|c|c|c|}
\hline \multicolumn{3}{|c|}{ Characteristics } & $\begin{array}{l}\text { Investigate } \\
\text { samples }\end{array}$ & $\begin{array}{l}\text { Percentage } \\
(\%)\end{array}$ \\
\hline \multirow{2}{*}{\multicolumn{2}{|c|}{ Over all Prevalence }} & Normal & $23621 / 23902$ & 98.82 \\
\hline & & Infected & $281 / 23902$ & 01.17 \\
\hline \multirow{4}{*}{$\operatorname{Sex}^{\mathrm{a}}$} & \multirow{2}{*}{$\begin{array}{l}\text { Male } \\
(11685)\end{array}$} & Normal & 11560 & 48.94 \\
\hline & & Infected & 125 & 44.48 \\
\hline & \multirow{2}{*}{$\begin{array}{l}\text { Female } \\
(12217)\end{array}$} & Normal & 12061 & 51.06 \\
\hline & & Infected & 156 & 55.51 \\
\hline \multirow{6}{*}{$\begin{array}{l}\text { Age } \\
\text { (year) }^{b}\end{array}$} & \multirow{2}{*}{$\begin{array}{l}<1 \text { year } \\
(7572)\end{array}$} & Normal & 7520 & 31.84 \\
\hline & & Infected & 52 & 18.50 \\
\hline & \multirow{2}{*}{$\begin{array}{l}1-2 \text { years } \\
(7349)\end{array}$} & Normal & 7262 & 30.74 \\
\hline & & Infected & 87 & 30.96 \\
\hline & \multirow{2}{*}{$\begin{array}{l}>2 \text { years } \\
(8981)\end{array}$} & Normal & 8839 & 37.42 \\
\hline & & Infected & 142 & 50.53 \\
\hline
\end{tabular}

${ }^{\mathrm{a}}$ Chi Squares for the effect of sex on hydatid prevalence (Value $=2.206)$, is high significant $(\mathrm{P}=<0.05)$.

${ }^{\mathrm{b}} \mathrm{Chi}$ Squares for the effect of age on hydatid prevalence (Value $=28.292)$, is high significant $(\mathrm{P}=<0.05)$

\subsection{Histopathological Findings}

Examination of H\&E-stained sections of normal non infected sheep showed renal cortex containing renal corpuscles, proximal (PCT) and distal convoluted tubules (DCT). The renal corpuscle was composed of a glomerulus formed of a lobulated capillary

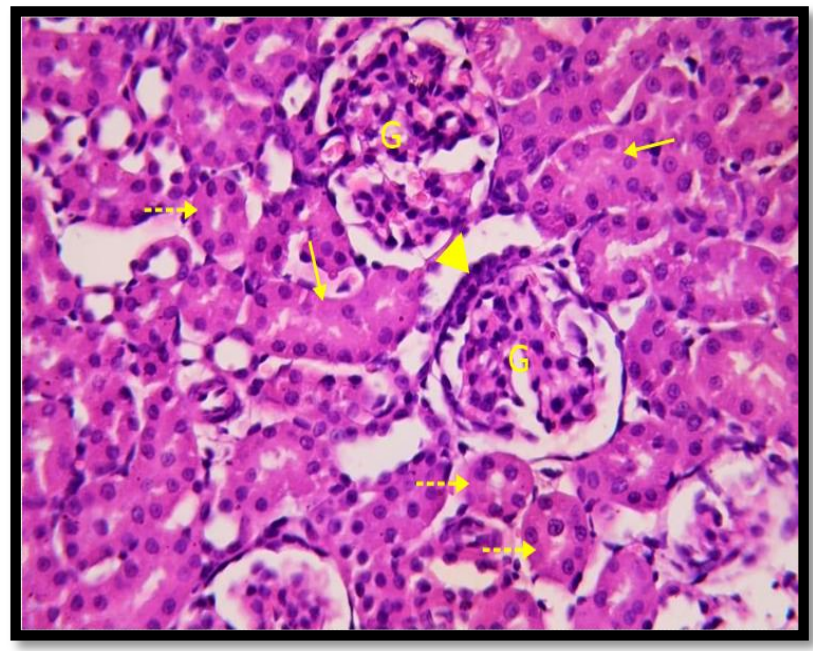

Figure $1 \mathrm{~A}$ photomicrograph $(\mathrm{H} \& \mathrm{E} \times 400)$ of a section of the renal cortex from control group showing renal glomeruli $(\mathrm{G})$, proximal convoluted tubules (red dot $\uparrow$ ), distal convoluted tubule (red $\uparrow$ ), and macula densa ( $\boldsymbol{\Delta}$ red). enveloped by Bowman's capsule. The PCTs were seen more numerous having narrow lumina and lined by columnar cells with indefinite cell boundaries. Their cytoplasm was strongly acidophilic with rounded vesicular nuclei. The DCTs were apparently less numerous than the PCTs in the renal cortex. They had relatively wider lumen and were lined by cubical cells with faint acidophilic cytoplasm and apical rounded vesicular nuclei (Figures 1-4).

The sections of infected sheep kidney stained by H\&E showed sever degenerative changes in renal tubules in the cortex as destruction in lining epithelial cell and loss brush border in P.T. There was exfoliated cellular debris in lumen of tubules. Cells of renal tubules showed dense nuclei and cytoplasmic vacuolation, some cells showed separation from basement membrane. Atrophy of the renal glomeruli with wide Bowman's space was detected. Some renal tubules showed shedding of their epithelial cells in the lumen. Intraluminal homogenous acidophilic hyaline casts were detected. Moreover, pyknotic and karyolitic nuclei were seen in some tubular epithelial cells. There were interstitial cells infiltration, intratubular cell debris, exfoliation and extrusion of some epithelial tubular cells and sever congestion in blood capillaries between tubules (Figures 5-17).

\section{Discussion}

Echinococcosis is one of the most common health problems and causes serious economic losses throughout the world (World Health Organization, 2015). Present study included the survey of hydatidosis infected sheep in slaughterhouse of Jeddah, Saudi Arabia

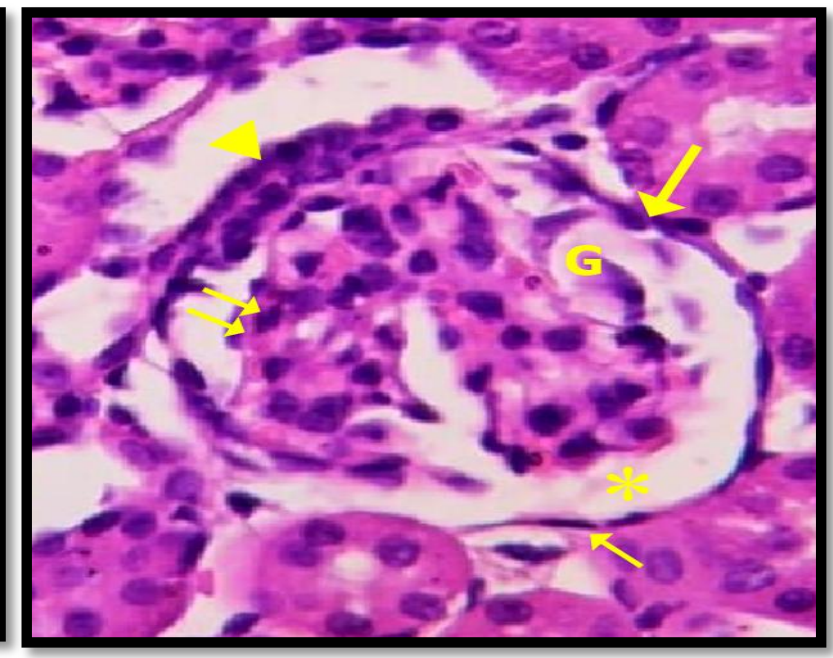

Figure 2 A photomicrograph $(H \& E \times 400)$ of a section of renal cortex from noninfected sheep showing renal glomeruli $(G)$, Parietal layer $(\uparrow)$, Visceral layer $(\uparrow \uparrow)$, Bowman's space $(*)$, and macula densa $(\mathbf{\Lambda})$. 


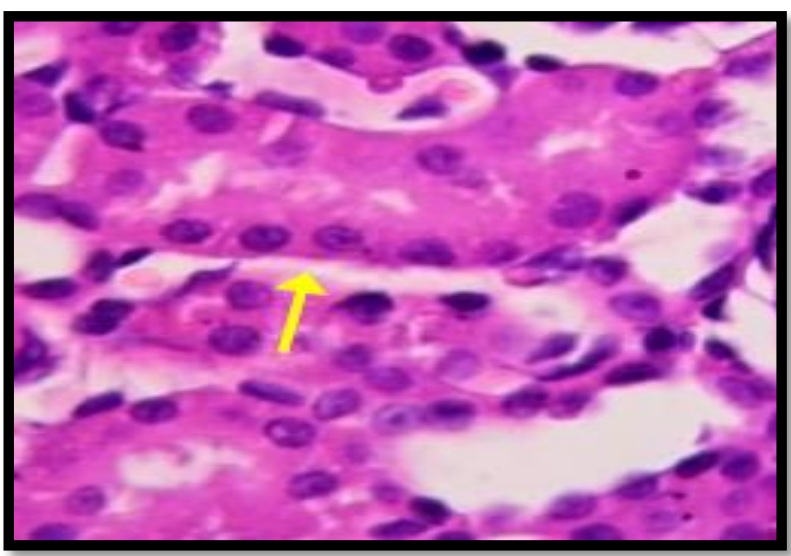

Figure $3 \mathrm{~A}$ photomicrograph of a section of the renal cortex from noninfected sheep showing proximal convoluted tubules $(\uparrow)$ and its Brush border $(\mathrm{H} \& \mathrm{E} \times 400)$.

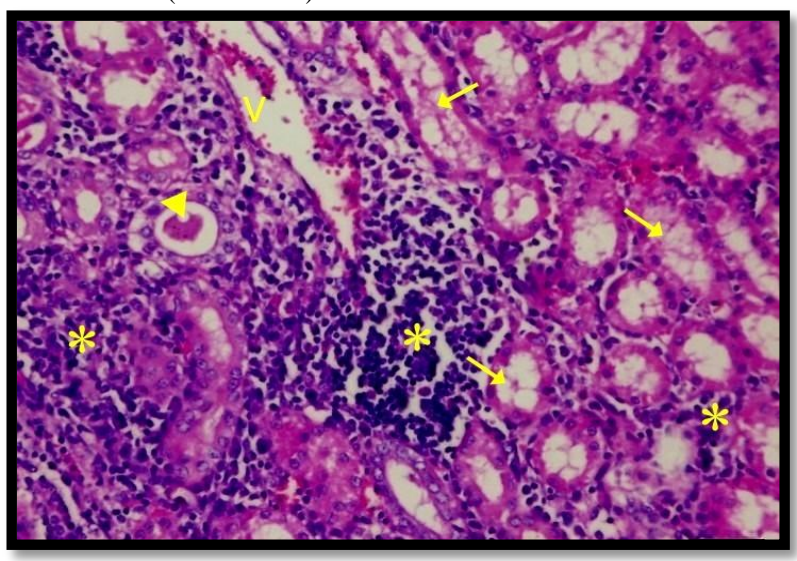

Figure 5 A Photomicrograph of the kidney (infected with hydatid cyst) stained by Hx\&E (X400) showing: proximal tubules loss their brush border and there is vacuolation in their cytoplasm, intratubular acidophilic deposition, capillaries congestion between renal tubules $(\mathrm{V})$, and mononuclear cellular infiltration between degenerated tubule and renal corpuscles.

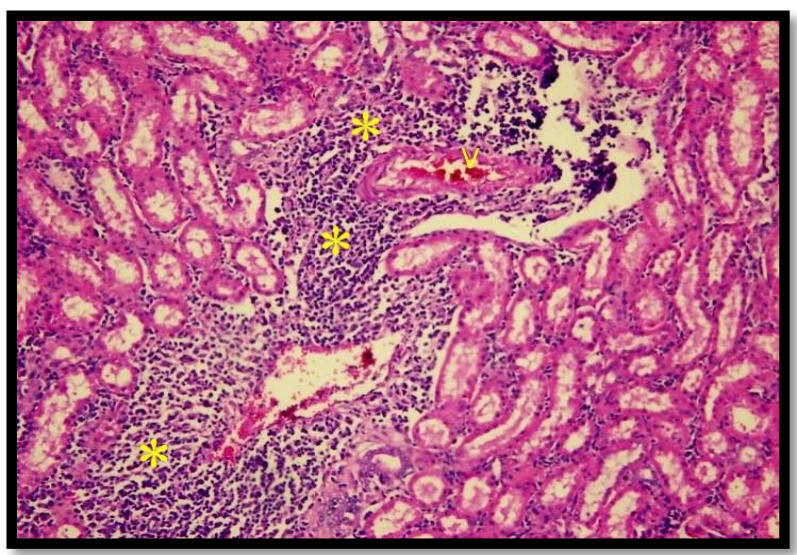

Figure 7 A photomicrograph of a section of the renal cortex from infected sheep showing mononuclear cellular infiltration between degenerated tubule and renal corpuscles $(*)$ and congested dilated blood vessels (V) $(\mathrm{H} \& \mathrm{E} \times 400)$.

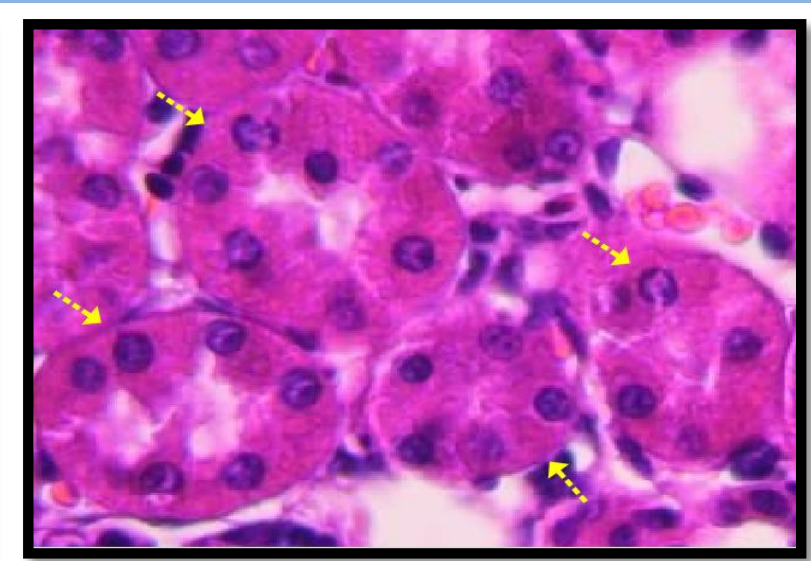

Figure 4 A photomicrograph $(\mathrm{H} \& \mathrm{E} \times 400)$ of the renal cortex section of control group showing renal distal convoluted tubule $(\operatorname{dot} \uparrow)$.

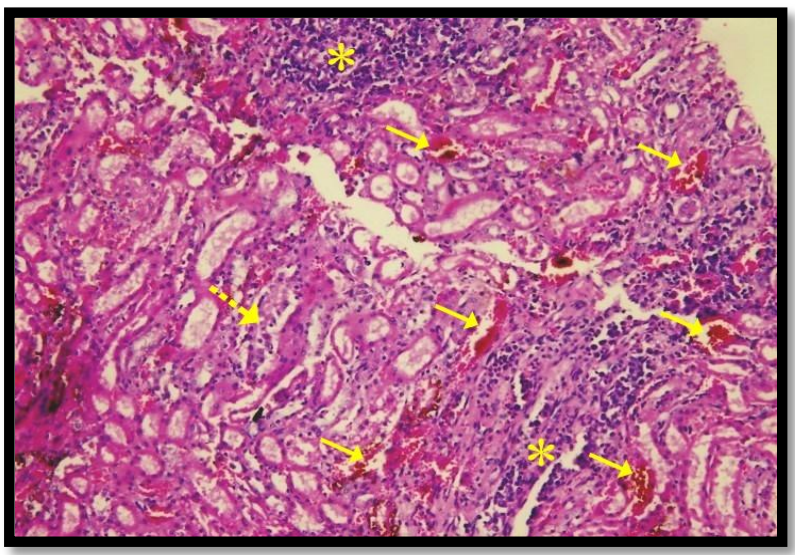

Figure 6 A photomicrograph of a section of the renal cortex from infected sheep showing interstitial hemorrhage (yellow $\uparrow$ ) and exfoliation of some lining epithelial cells of some tubules. Notice: mononuclear cellular infiltration between degenerated tubule and renal corpuscles $(\mathrm{H} \& \mathrm{E} \times 400)$.

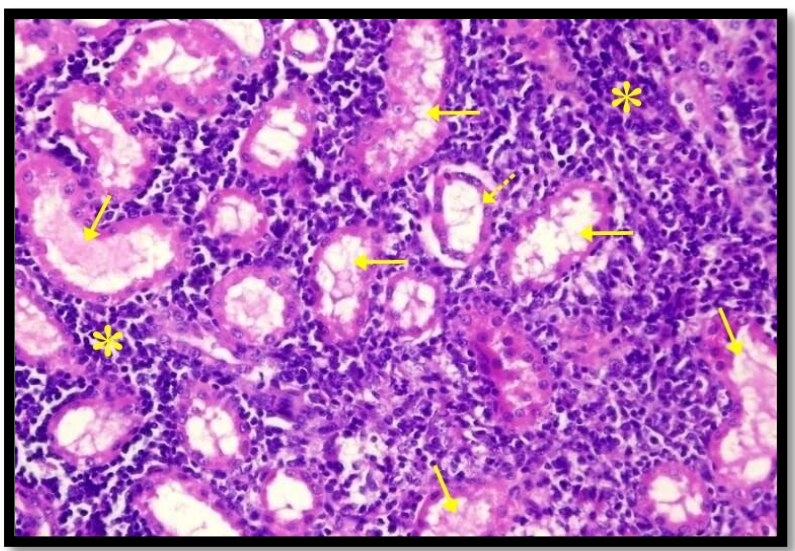

Figure 8 A Photomicrograph of the kidney (infected with hydatid cyst) stained by Hx\&E (X400) showing: proximal tubules with loss their brush border and there is vacuolation of their cytoplasm $(\uparrow)$, exfoliation of some lining epithelial cells of some tubules (dot $\uparrow)$, and mononuclear cellular infiltration between degenerated tubule and renal corpuscles $(*)$.

Journal of Experimental Biology and Agricultural Sciences http://www.jebas.org 


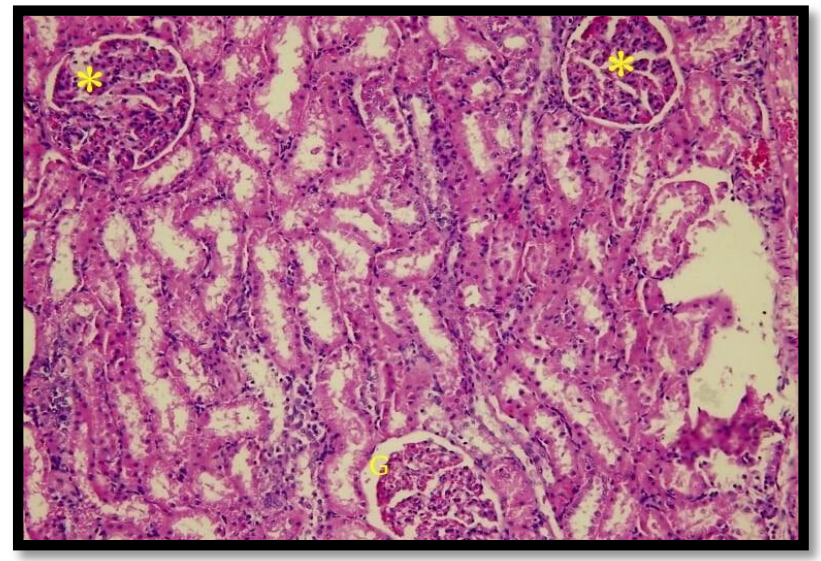

Figure 9 A photomicrograph of a renal cortex section of infected sheep showing Glomerular tuft area was shrunken accompanied by reduction of capillary and some with extravasation of the blood (*) $(\mathrm{H} \& \mathrm{E} \times 400)$.

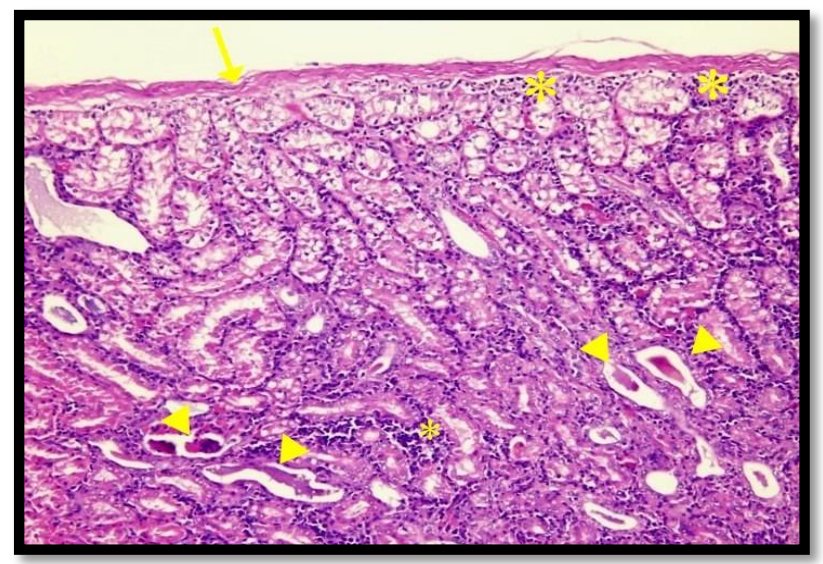

Figure 11 A photomicrograph of the renal cortex section of the infected sheep showing mononuclear cellular infiltration between degenerated tubule and renal corpuscles $(*)$ and thick capsule $(\boldsymbol{\Lambda})$. Notice intratubular acidophilic deposition $(H \& E \times 200)$.

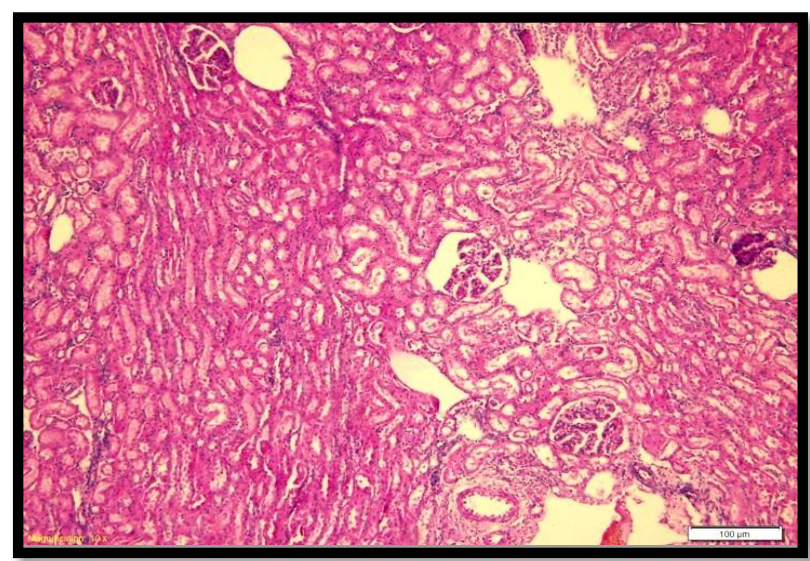

Figure 13 A photomicrograph of renal cortex section of infected sheep showing glomerular tuft area was shrunken $(H \& E \times 200)$.

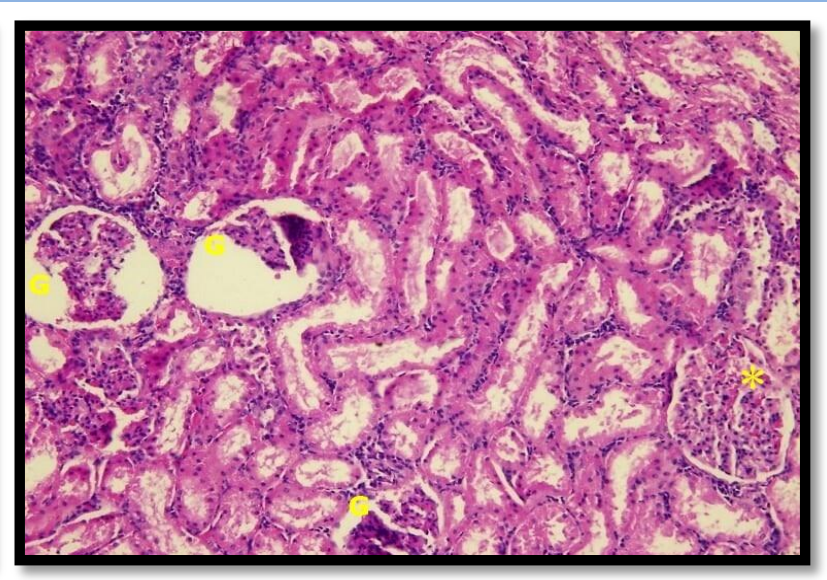

Figure 10 A photomicrograph of renal cortex section of the infected sheep showing Glomerular tuft area was shrunken accompanied by reduction of capillary and some with extravasation of the blood (*) $(\mathrm{H} \& \mathrm{E} \times 400)$.

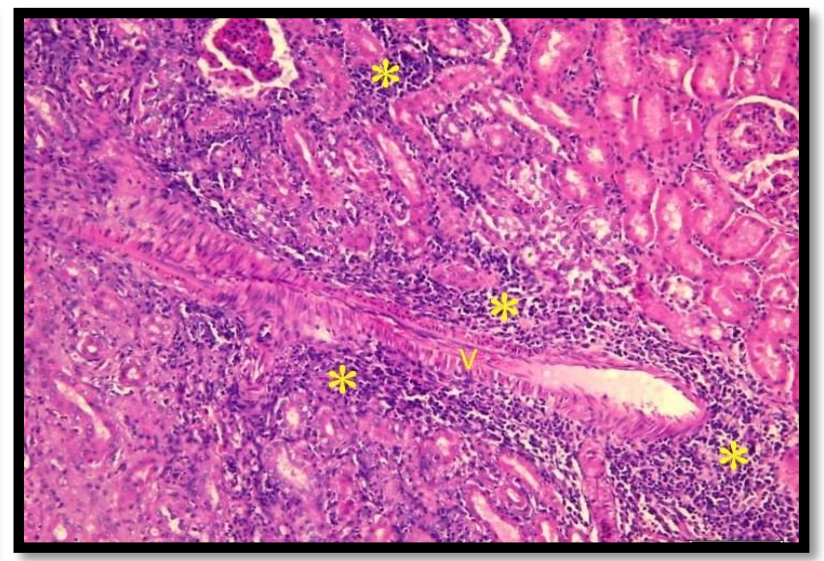

Figure 12 A photomicrograph of renal cortex section of the infected sheep showing longitudinally cut blood vessel $(\mathrm{V})$ with mononuclear cellularly infiltrated wall also seen $(*)(H \& E \times 200)$.

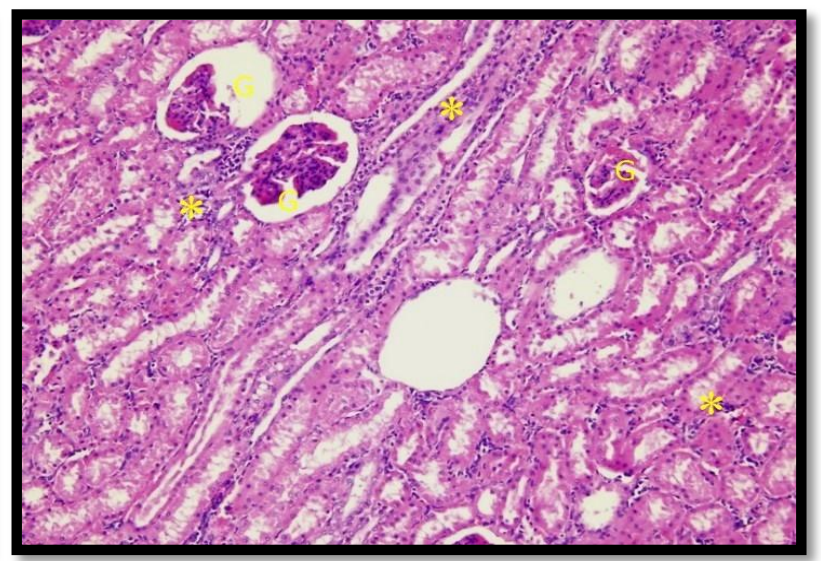

Figure 14 A photomicrograph of higher magnification of the previous section in the renal cortex of infected sheep showing glomerular tuft area was shrunken accompanied by reduction of capillary diameter and mononuclear cell infiltrations $(*)$.

Journal of Experimental Biology and Agricultural Sciences http://www.jebas.org 


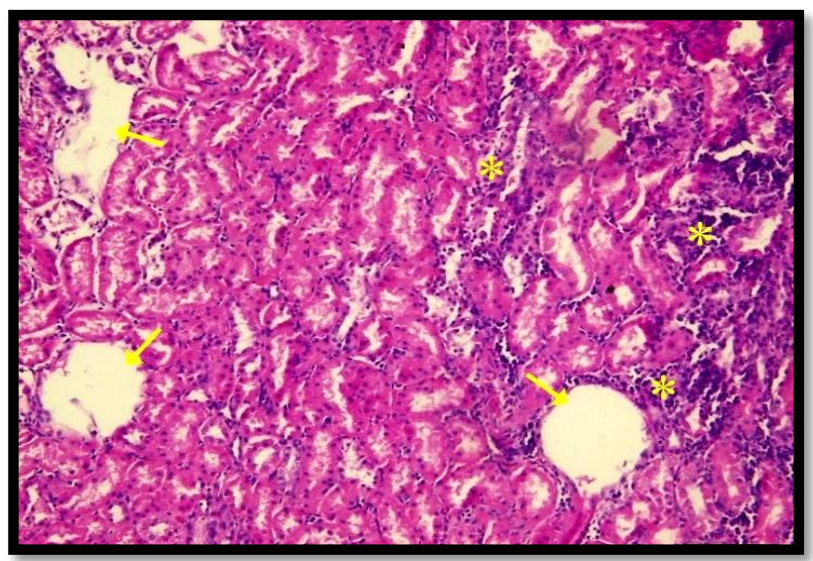

Figure 15 A photomicrograph of renal cortex section of the infected sheep showing marked reduction of the renal corpuscles $(\uparrow)$ accompanied by mononuclear cell infiltrations $(*)(\mathrm{H} \& \mathrm{E} \times 400)$.

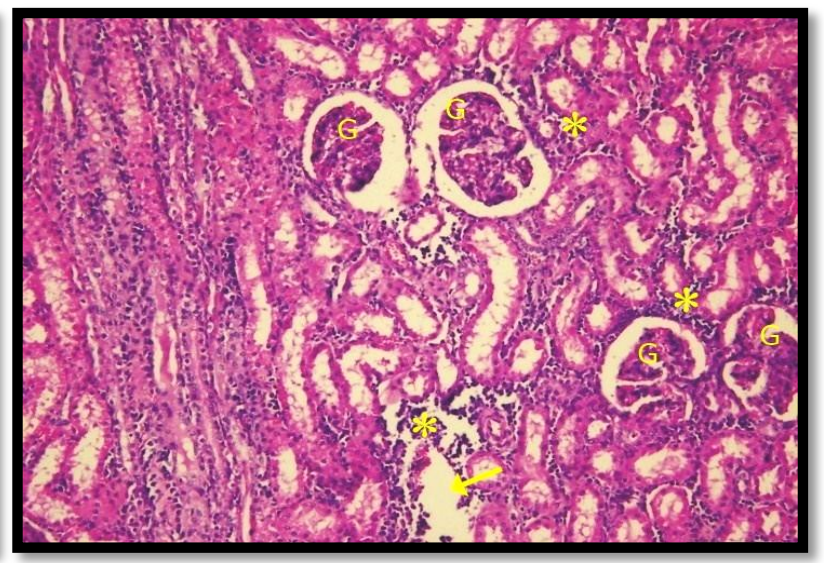

Figure 16A photomicrograph of renal cortex section of the infected sheep showing glomerular $(\mathrm{G})$ tuft area was shrunken accompanied by areas with no renal corpuscles $(\uparrow)$. Notice mononuclear cell infiltrations $(*)(\mathrm{H} \& \mathrm{E} \times 400)$.

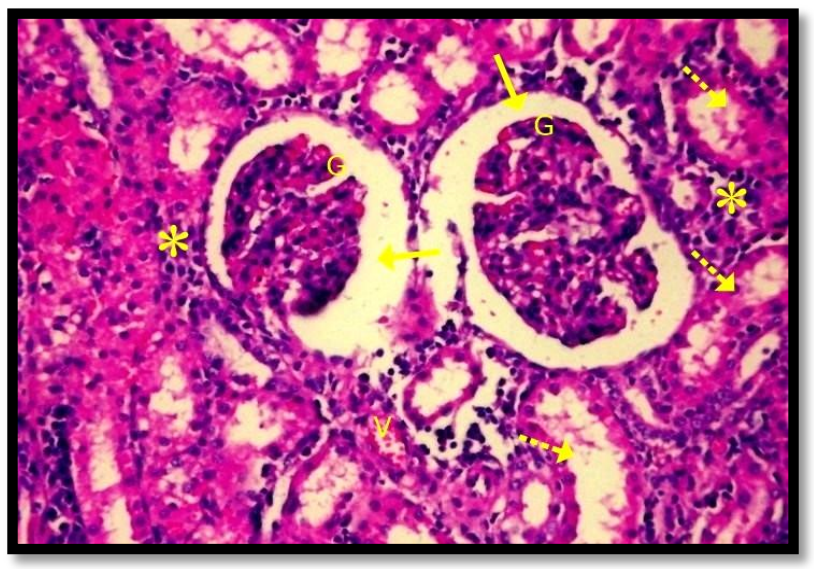

Figure 17 A Photomicrograph of the kidney (infected with hydatid cyst) stained by Hx\&E ( $\times 400)$ showing: proximal tubules with vacuolation of their cytoplasm $(\operatorname{dot} \uparrow)$, and mononuclear cellular infiltration between degenerated tubule and renal corpuscles $(*)$. Notice congested blood vessels $(\mathrm{V})$, glomerular $(\mathrm{G})$ tuft area was shrunken accompanied by reduction of capillary diameter and wide bowman's space ( $\uparrow$ ).

and reported $1.17 \%(281 / 23902)$ kidney infection prevalence. These findings are contradictory to the findings of previous researchers from Saudi Arabia those who reported higher prevalence rate of infection in $\mathrm{Al}$ Baha (12.61\%) and $\mathrm{Al}$ Taif (13.5\%) (Ibrahim, 2010; Hayajneh et al., 2014). These variables results may be due to various factors affecting the transmission between farm animals in these areas. However, findings of Almalki et al. (2017) are in agreement with the findings of present study those who reported lower prevalence $(1.06 \%)$ in Sawakny sheep in Riyadh. Moreover, Toulah et al. (2012) conducted study in Jeddah and reported that camels have higher prevalence, and this was followed by the cattle, sheep and goats. This decline was attributed to the fact that perfections in living conditions and increased realization of the risk of diseases have contributed to the decrease of rate of infection in Jeddah and Riyadh (Toulah et al., 2017; Almalki et al., 2017).

Moreover, the present study showed that hydatid infection is significantly increased in females (55.51) than males (44.48). According to Roostaei et al. (2017) this variation might be due to a mix of different factors like hormones, genetic causes, and the interaction between the host and the parasite.

In present study, prevalence of hydatid cysts for age group less than one year, 1-2 years and more than two years in sheep was reported as $18.50 \% 30.96 \%$ and $50.53 \%$ respectively. Results are in agreement with the findings of Ibrahim (2010); Al-Qurashi \& Bahnass (2012); Elmajdoub \& Rahman (2015), those who suggested that higher incidence of infection were reported in old 
animals as compared to young one. These observations attribute to the long exposure of sheep infected by E. granulosus. Abunna et al. (2012) and Khan et al. (2013) reported a positive correlation between the rate of infection and the age of the animal which has great value in the field of preventive medicine and in reducing the risk of the zoonotic diseases. Contrary to this, Hayajneh et al. (2014) and Almalki et al. (2017) have reported higher prevalence in young sheep than the old sheep.

In the current study, the histopathological examination of the uninfected sheep (control normal animals) showed the renal glomeruli, proximal convoluted tubules, distal convoluted tubule, and macula densa. These results confirmed by Maurya et al. (2018) who mentioned the normal histological structures of the kidney. Infected sheep histopathological evaluation of kidney showed the separation of the epithelial lining of tubular cells from their basement membrane. This might be due to reallocation or alteration of the integrin that proves the tubular cells and cause cell detachment from the basement membrane (Kumar et al., 2014).

The renal interstitium of infected sheep with hydatid cyst of the current study revealed sever mononuclear cellular infiltration, congested dilated blood vessels and interstitial hemorrhage. The death of tubular cells by necrosis may be used to recruit inflammatory cells, including macrophages and leukocytes. In addition, renal endothelial cell loss and renal dysfunction and may be the cause of the extravasation of red blood cells (RBCs), congestion of glomerular and dilatation of peritubular capillaries seen in infected sheep (Duffield, 2014). The vacuolation in the cytoplasm of renal tubules described as a kind of cellular defensive mechanism against injurious substances (Abdel Hameed, 2004). In addition Cheville (2009) explained that these vacuoles are responsible for collecting harmful elements and preventing them from interfering with the biological activities of these cells.

\section{Conclusion}

This study showed a significantly less incidence of infected kidney disease among sheep in Jeddah compared to previous studies in other locations in Saudi Arabia, which reflects the variation in the rate of infection in rural or urban areas. This increased rate of infection in females and age group more than 2 years of the infected kidney have an epidemiological significance since they suggest an increased potential for transmission and thus the continuation of the hydatidosis life cycle.

It is therefore recommended to take further measures to control the hydatid disease in Jeddah. To achieve this goal, it is recommended to follow the strongest slaughter process together with the treatment of stray dogs because the stray dog sact as a definitive host for E. granulosus and plays an important role in the spread of infection via contamination of the environment. Further efforts should be made to control the carriage of infection from slaughterhouses by safe disposal of infected waste.

\section{Acknowledgements}

The research was carried out with the willand cooperation of slaughterhouse workers and owners of the slaughtered animals. All contributions are gratefully acknowledged.

\section{Conflict of Interest}

Authors would hereby like to declare that there is no conflict of interests that could possibly arise.

\section{References}

Abdel Hameed TF (2004) Light and electron microscopic studies on the effect of orally-adminstered formalin on liver and kidney of guinea pig. Journal-Egyptian German Society of Zoology 45: 203-224.

Abdel-Baki AAS, Almalki E, Al-Quarishy S (2018) Prevalence and characterization of hydatidosis in Najdi sheep slaughtered in Riyadh city, Saudi Arabia. Saudi Journal of Biological Sciences 25: 1375-1379.

Abdel-Baki AAS, Almalki E, Mansour L, Al-Quarishy S (2016) In vitro scolicidal effects of Salvadora persica root extract against protoscolices of Echinococcus granulosus. The Korean Journal of Parasitology 54: 61.

Abunna F, Fentaye S, Megersa B, Regassa A (2012) Prevalence of bovine hydatidosis in Kombolcha ELFORA abattoir, North Eastern Ethiopia. Open Journal of Animal Sciences 2: 281.

Almalki E, Al-Quarishy S, Abdel-Baki AAS (2017) Assessment of prevalence of hydatidosis in slaughtered Sawakny sheep in Riyadh city, Saudi Arabia. Saudi Journal of Biological Sciences 24: 1534-1537.

Al-Qurashi AM, Bahnass MM (2012) Some epidemiological and serological studies on hydatidosis in Najran region. Journal of American Science 8: 918-921.

Bancroft JD, Gamble M (2008) Theory and practice in histological techniques. 6th ed.; Churchill Livingstone, 2008, Pp. 121-186. Bookmark: https://trove.nla.gov.au/version/227531793.

Cheville NF (2009) Ultrastructural pathology: the comparative cellular basis of disease. 2nd. Wiley Blackwell. A john Wiley of Sons, Inc USA. John Wiley \& Sons.

Craig P, Mastin A, van Kesteren F, Boufana B (2015) Echinococcus granulosus: epidemiology and state-of-the-art of diagnostics in animals. Veterinary Parasitology 213: 132-148.

Duffield JS (2014) Cellular and molecular mechanisms in kidney fibrosis. The Journal of Clinical Investigation 124: 2299-2306. 
El-Ghareeb WR, Edris AM, Alfifi AE, Ibrahim AM (2017) Prevalence and Histopathological Studies on Hydatidosis among Sheep Carcasses at Al-Ahsa, Saudi Arabia. Alexandria Journal for Veterinary Sciences 55:146-153.

Elmajdoub LO, Rahman WA (2015) Prevalence of hydatid cysts in slaughtered animals from different areas of Libya. Open Journal of Veterinary Medicine 5: 1-10.

Hayajneh FMF, Althomali AMH, Nasr AT (2014) Prevalence and characterization of hydatidosis in animals slaughtered at Al Taif abattoir, Kingdom of Saudi Arabia. Open Journal of Animal Sciences 4: 38-41.

Ibrahim MM (2010) Study of cystic echinococcosis in slaughtered animals in Al Baha region, Saudi Arabia: interaction between some biotic and abiotic factors. Acta Tropica 113: 26-33.

Khan AM, Gazi M, Bashir S (2013) Seasonal prevalence of hydatidosis in buffaloes-A retrospective study. Veterinary World 6: 647-650.

Kumar V, Abbas AK, Fausto N, Aster JC (2014) Robbins and Cotran pathologic basis of disease, professional edition e-book. Elsevier Health sciences. Inc, 10 th edition 2014; Pp. 537- 538.

Maurya H, Kumar T, Kumar S (2018) Anatomical and Physiological Similarities of Kidney in Different Experimental Animals Used for Basic Studies. Journal of Clinical \& Experimental Nephrology 3: 09. doi: 10.21767/2472-5056.100060.

Nakao M, Lavikainen A, Yanagida T, Ito A (2013) Phylogenetic systematics of the genus Echinococcus (Cestoda: Taeniidae). International Journal for Parasitology 43(12-13): 1017-1029.

Romig T, Ebi D, Wassermann M (2015) Taxonomy and molecular epidemiology of Echinococcus granulosussensulato. Veterinary
Parasitology 213: 76-84. doi: 10.1016/j.vetpar.2015.07.035.

Roostaei M, Fallah M, Maghsood AH, Saidijam M, Matini M (2017) Prevalence and fertility survey of hydatid cyst in slaughtered livestock in Hamadan abattoir, Western Iran, 20152016. Avicenna Journal of Clinical Microbiology and Infection 4: e43361.

Schurer J, Shury T, Leighton F, Jenkins E (2013) Surveillance for Echinococcus canadensis genotypes in Canadian ungulates. International Journal for Parasitology: Parasites and Wildlife 2: 97-101.

Toulah FH, El Shafei AA, Alsolam MN (2012) Prevalence of hydatidosis among slaughtered animals in Jeddah, Kingdom of Saudi Arabia. Journal of the Egyptian Society of Parasitology 240(1411):1-10.

Toulah FH, El Shafi AA, Naem M (2017) Hydatidosis among Imported Animals in Jeddah, Saudi Arabia. Journal of Liver and Clinical Research 4:1031.

World Health Organization (1993) Report of WHO Working Group Meeting on Echinococcosis Research and Control, Beijing, China, 12 October 1993 (No. VPH/93.131). World Health Organization, Geneva.

World Health Organization (2015) Investing to overcome the global impact of neglected tropical diseases: third WHO report on neglected tropical diseases 2015 (Vol. 3). World Health Organization.

Yang S, Wu W, Tian T, Zhao J, Chen K, Wang Q, Feng Z (2015) Prevalence of cystic echinococcosis in slaughtered sheep as an indicator to assess control progress in Emin County, Xinjiang, China. The Korean Jjournal of Parasitology 53: 355-359. doi:10.3347/kjp.2015.53.3.355. 